\title{
Enlarged Mediastinal Lymph Nodes in Computed Tomography are a Valuable Prognostic Factor in Non-Small Cell Lung Cancer Patients with Pathologically Negative Lymph Nodes
}

This article was published in the following Dove Press journal:

Cancer Management and Research

\author{
Yuansheng Zhengl,* \\ Yiwei Huang ${ }^{1} *$ \\ Guoshu $\mathrm{Bi}$ (D) $^{1, *}$ \\ Zhencong Chen' \\ Tao Lu' \\ Songtao $\mathrm{Xu}^{1,2}$ \\ Cheng Zhan (D) \\ Qun Wang (D)
}

'Department of Thoracic Surgery, Zhongshan Hospital, Fudan University, Shanghai City, People's Republic of China; ${ }^{2}$ Department of Thoracic Surgery, Xiamen Branch, Zhongshan Hospital, Fudan University, Xiamen City, Fujian Province, People's Republic of China

*These authors contributed equally to this work
Correspondence: Cheng Zhan; Qun Wang Department of Thoracic Surgery,

Zhongshan Hospital, Fudan University, No.

180, Fenglin Road, Shanghai 200032, People's Republic of China

$\mathrm{Tel} / \mathrm{Fax}+86-2 \mathrm{I}-64041990$

Email czhan 10@fudan.edu.cn;

wang.qun@zs-hospital.sh.cn
Background: Most non-small cell lung cancer patients with enlarged mediastinal lymph nodes (LN) in preoperative computer tomography (CT) images are diagnosed with N0 in the pathological examination after surgery. However, these patients seem to have worse survival than those without enlarged mediastinal LN in our clinical practice. This study aimed to investigate whether the size of mediastinal $\mathrm{LN}$ is correlated with the prognosis in pathological N0 patients, which could help us to predict the prognoses further.

Methods: The retrospective cohort study involved $758 \mathrm{~N} 0$ patients with a thin layer CT scan. We have measured the size of mediastinal LN, including long diameter, short diameter, and volume on CT image, and classified patients by X-tile. Next, we explored the risk factors of enlarged LN by univariate and multivariate logistic analysis. Then, we have compared the 5 -year cancer-specific survival by Kaplan-Meier and log-rank method. Multivariate Cox analysis was utilized to further survival analysis. Finally, we have constructed the prediction model by nomogram.

Results: A total of 150 N0 patients (19.8\%) had mediastinal LN enlargement in our study. After multivariate logistic analysis, we found the LN enlargement was significantly correlated with age $(p=0.001)$, pathology $(p<0.001)$ and tumor recurrence $(p<0.001)$. The patients with LN enlargement had a worse 5-year cancer-specific survival $(75.3 \%$ vs $92.8 \%, \mathrm{p}<0.001)$ after Kaplan-Meier analysis. Patients with a larger volume had increased risk of tumor-associated death when compared with the normal group $(\mathrm{p}<0.001)$ by multivariate Cox analyses.

Conclusion: N0 patients with larger mediastinal LN had a worse 5-year cancer-specific survival and a higher risk of recurrence. The volume of LN was the most valuable prognostic factor in N0 patients.

Keywords: mediastinal lymph nodes, enlarged, prognosis, computed tomography

\section{Introduction}

Non-small cell lung cancer (NSCLC) is the most commonly diagnosed cancer worldwide, and the 5-year overall survival is still relatively low, which has caused an enormous medical burden. ${ }^{1,2}$ Many patients are diagnosed with cancer in an advanced stage, and the precise tumor node metastasis stage is related to therapy and prognosis. ${ }^{3}$ The presence and anatomical extent of histologically confirmed lymph node (LN) metastases are critical prognostic factors. ${ }^{4,5}$ Mediastinal LN () involvement is reported to be present in about one-third of these cases at the time of initial diagnosis. 
A mediastinum LN staging (N-staging) of non-small cell lung cancer (NSCLC) is essential in choosing the treatment course. The main sign for predicting LN involvement before surgery is still enlargement; the primary means of detection before surgery is, therefore, computed tomography (CT). CT provides the most detailed imaging information, so it is generally used as a routine imaging procedure in the tumor node metastasis (TNM) staging of patients with lung cancer. ${ }^{6}$ Chest CT images usually show the tumor size and the mediastinal space. Many studies have investigated the predictive value of CT in $\mathrm{N}$ staging. It is for this reason that $\mathrm{CT}$ chest is standard of care in preoperative assessment, as is PET-CT scan. A few studies suggested the bulky mediastinal LN could cause worse survival in N2 staging patients. ${ }^{7-9}$ Some studies reported that different parameters of LN measured by CT improved the predictive value of evaluating mediastinum LN in lung cancer. ${ }^{10}$ However, more than half of patients with mediastinum LN enlargement had no LN metastasis.

Among most previous studies, the standard for the diagnosis of LN enlargement was more than the $6-8 \mathrm{~mm}$ for a short diameter or more than $10-15 \mathrm{~mm}$ for a long diameter, but there is still no consensus. ${ }^{11-14}$ Although a few studies have mentioned the size of mediastinum LN, few studies have used the short diameter or other parameters of mediastinum LN. Most studies were mainly concerned about the relationship of $\mathrm{LN}$ enlargement to $\mathrm{LN}$ metastasis or the LN positive percentage. Still, few studies mentioned the prognoses in LN enlargement patients without LN metastasis. The aim of the present study was, therefore, to determine whether the size of negative mediastinum LN before surgery, measured by CT which underwent in one month before surgery, including the long diameter, short diameter, and volume were prognostic factors in patients with NSCLC in N0 stages, which could provide a new reference for the mechanism exploration and further therapies.

\section{Methods}

\section{Approval}

Our study was approved by the Ethics Committee of Zhongshan Hospital (B2017-115), Fudan University in Shanghai, and complied with the Declaration of Helsinki. The patient consent to review their medical records was waived because our study was a retrospective noninterventive study, which did no harm to patients. The scans and patient information were strictly confidential to prevent linkage. The information in databases was permitted from the dataset owner. The data were collected from NSCLC patients who were treated with radical surgery of lung cancer and lymphadenectomy in the Department of Thoracic Surgery, Zhongshan Hospital in Shanghai, from January 1, 2013, to December 31, 2014. Every patient has received complete care in preoperative assessment according to the National Comprehensive Cancer Network (NCCN) guideline. The lung cancer patients with a thin layer CT scan (1 layer per $1 \mathrm{~mm}$ ) in 1 month before surgery and pathological N0 staging based on the surgical specimen were included in our study. The patients with positive LN, Tx staging, M1 or Mx staging, benign tumors, or metastasis carcinomas confirmed by postoperative pathology were excluded. We also reevaluated the stage of patients according to the eighth edition of the American Joint Committee on Cancer TNM staging. The N0 patients with LN enlargement have received endobronchial ultrasound (EBUS) before surgery, and the results were negative $35.0 \%(265 / 758)$ patients had a PET/CT scan before surgery in our study. Only four patients had intraoperative mediastinoscopy.

\section{Follow-Up and Data Collection}

The general information of patients was obtained from medical records in the hospital, and the disease association details were obtained during the perioperative and postoperative periods. The patients were followed up with chest CT every three months in the first year and every six months in the second year. Then the patients were followed up with CT every 6 12 months a year. The last follow-up was carried out in December 2019, and the median follow-up time was 56 months. At the same time, the overall survival (OS) data, including cancer-specific survival data, recurrence data, and therapy data, was updated based on information obtained from telephone or direct outpatient clinical visits every six months a year. The primary ending points of the follow-up involved the death of patients, and the secondary endpoints were cancer recurrence. Survival time was censored at the date of lost follow-up, the last contact, and the date of death from other causes, whichever came first.

\section{Classification of LN}

All patients in our study had a thin chest layer CT scan (1 layer per $1 \mathrm{~mm}$ ) in 1 month before surgery, and will receive a surgery therapy after TNM staging. We have measured 
Table I Patient Characteristics According to the Status of CT Lymph Nodes

\begin{tabular}{|c|c|c|c|c|}
\hline Variables & No. (\%) & Non-enlarged & Enlarged & \multirow[t]{2}{*}{$\mathbf{P}$} \\
\hline No. & $758(100)$ & $608(80.9)$ & $150(19.1)$ & \\
\hline Mean Age (SD) & 758 & $59.68(9.8 I)$ & $62.59(9.17)$ & 0.001 \\
\hline Sex & & & & $<0.001$ \\
\hline Female & 382 & $330(54.3)$ & $52(34.7)$ & \\
\hline Male & 376 & $278(45.7)$ & $98(65.3)$ & \\
\hline Smoking & & & & $<0.001$ \\
\hline Yes & 161 & $110(18.1)$ & $51(34.0)$ & \\
\hline No & 597 & $498(81.9)$ & $99(66.0)$ & \\
\hline Family history & & & & 1 \\
\hline Yes & 30 & $24(3.9)$ & $6(4.0)$ & \\
\hline No & 728 & $584(96.1)$ & $144(96.0)$ & \\
\hline Pathology & & & & $<0.001$ \\
\hline Squamous cell carcinoma & 102 & $58(9.5)$ & $44(29.3)$ & \\
\hline Adenocarcinoma & 610 & $513(84.4)$ & $97(64.7)$ & \\
\hline Others & 46 & $37(6.1)$ & $9(6.0)$ & \\
\hline T stage & & & & $<0.001$ \\
\hline TI & 403 & $347(57.1)$ & $56(37.3)$ & \\
\hline $\mathrm{T} 2$ & 310 & $234(38.5)$ & $76(50.7)$ & \\
\hline T3 & 41 & $25(4.1)$ & $16(10.7$ & \\
\hline T4 & 4 & $2(0.3)$ & $2(1.3)$ & \\
\hline Adjuvant therapy & & & & 0.001 \\
\hline Yes & 210 & $152(25.0)$ & $58(38.7)$ & \\
\hline No & 548 & $456(75.0)$ & $92(61.3)$ & \\
\hline Recurrence & & & & $<0.001$ \\
\hline Yes & 101 & $65(10.7)$ & $36(24.0)$ & \\
\hline No & 657 & $543(89.3)$ & II 4 (76.0) & \\
\hline
\end{tabular}

the long diameter and short diameter of enlarged mediastinal $\mathrm{LN}$ at the maximum section on $\mathrm{CT}$ directly. The definition of LN enlargement (LN enlargement) was a long diameter $>10 \mathrm{~mm}$ or short diameter $>6 \mathrm{~mm}$. The long axis and short axis diameters were measured in the maximal section, and the volume of $\mathrm{LN}$ was calculated using the formula, $\mathrm{V}=\pi / 6^{*}$ long diameter*short diameter^${ }^{\wedge} 2$. The LN of the normal group, therefore, included patients with non-enlarged LN (long diameter $<10 \mathrm{~mm}$ and short diameter $<6 \mathrm{~mm}$ ). In contrast, the $\mathrm{LN}$ enlargement group was comprised of patients with an enlarged LN. We used the X-tile, a software which can select the optimal division of the data by choosing the highest $\chi^{2}$ value, to obtain the best cut-off value (long diameter $=18 \mathrm{~mm}$, short diameter $=10 \mathrm{~mm}$, volume $\left.=600 \mathrm{~mm}^{3}\right) .{ }^{15}$ We divided the $\mathrm{LN}$ enlargement group into two subgroups according to the long diameter, short diameter, or volume.

\section{Statistical Analysis}

All analyses were performed with SPSS statistical software for Windows, version 24.0 (IBM, Armonk, NY, USA) and $\mathrm{R}$ software, version 3.6.1 ( $\mathrm{R}$ Foundation for Statistical Computing, Vienna, Austria). Categorical variables were compared using Fisher's exact test, and Student's $t$-test compared Pearson's Chi-squared test and continuous variables. Binary logistic regression analysis was performed to identify predictors for mediastinum LN enlargement. The KaplanMeier method with the Log rank test was used to compare 5-year CSS curves. Cox regression was used for univariable and multivariable analyses to compare the hazard ratios and constructed prediction model of CSS. A competitive risk model was conducted with R software using the "cmprsk" package to compare the cumulative risk of tumor-associated death and other death. All statistical tests were two-sided, and a value of $p<0.05$ was considered statistically significant. 


\section{Results}

A total of 758 NSCLC patients in N0 staging were analyzed in this study, including 376 males (49.6\%) and 382 females (50.4\%). According to the results from chest CT images, we divided the patients into two groups based on the size of the mediastinum LN, which included 150 patients (19.1\%) with LN enlargements and 608 patients (80.9\%) without LN enlargement. The baseline clinical characteristics are shown in Table 1. There was no significant difference in the family history of NSCLC $(p=1.000)$ between the two groups by Pearson's Chi-squared test based on Table 1. We had defined a positive family history of NSCLC when the biological relatives of patients had NSCLC. However, we found that the probability of LN enlargement in males $(\mathrm{p}<$ $0.001)$, aged $(\mathrm{p}=0.001)$ smoking $(\mathrm{p}<0.001)$, squamous cell carcinoma $(\mathrm{p}<0.001)$ and advanced $\mathrm{T}(\mathrm{p}<0.001)$, patients was higher by Fisher's exact test, Pearson's Chisquared test and Student's $t$-test (age). And after Pearson's Chi-squared test, we also found the LN enlargement patients had more risk of recurrence of cancer $(p<0.001)$, and patients with LN enlargement before surgery may have a high probability of adjuvant therapy after surgery ( $p<0.001)$. The lung $(44 / 102$ patients, 43\%) was the first recurrence site of all recurrence patients in our study (Supplementary Figure 1A).

\section{The Distribution and Risk Factors of LN Enlargement}

The standard of LN enlargement in our article was a long diameter $>10 \mathrm{~mm}$ or short diameter $>6 \mathrm{~mm}$. The grouping results based on different parameters, including long diameter, short diameter, and volume, are shown in Figure 1A. We also identified potential predictors of $\mathrm{LN}$ enlargement using univariate and multivariate logistics analyses (Supplement Table 1). We found that aging ( $\mathrm{p}=0.004)$, squamous cell carcinoma ( $\mathrm{p}=0.003)$, and advanced $\mathrm{T}$ stage $(p=0.045)$ were significant risk factors of $\mathrm{LN}$ enlargement. At the same time, there was no significant difference in sex $(\mathrm{p}=0.095)$ and smoking $(\mathrm{p}=0.428)$ in multivariate logistics analyses. The logistics analyses result also showed that LN enlargement had a higher risk of cancer recurrence ( $p$ $<0.001$ ), and the Figure 1B showed the first recurrence site

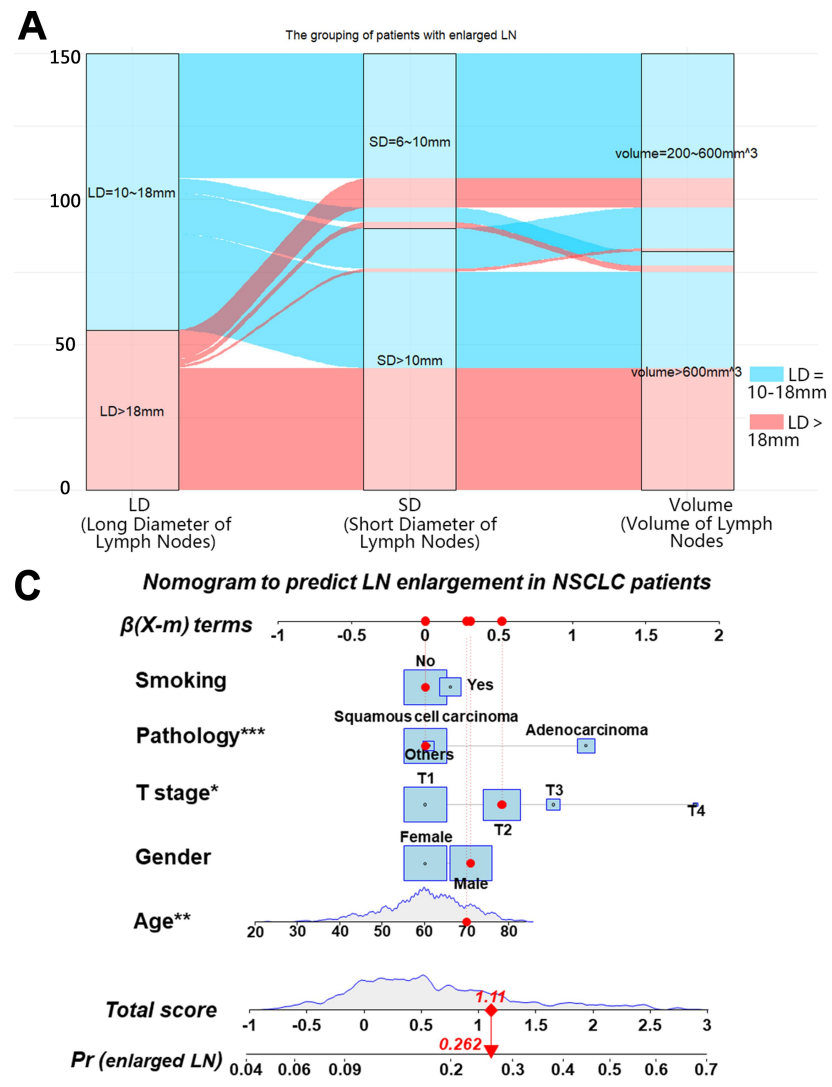

B

B First recurrence site of patients with LNE

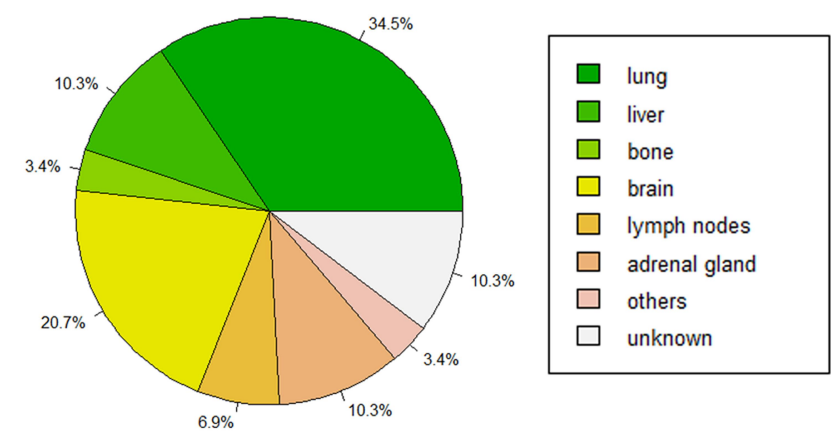

$\mathrm{LNE}=$ lymph nodes enlargement

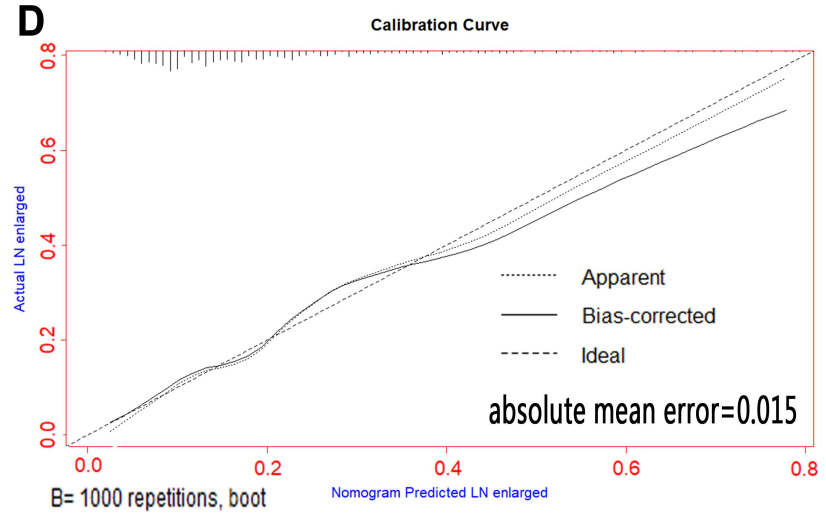

Figure I The distribution of enlarged LN in different size (A). The pie of the first recurrence site of patients with LN enlargement (B). The nomogram to predict LN enlargement risk of patients with NSCLC (C) and calibration plots (D). ${ }^{*}<<0.05$; ${ }^{*} \mathrm{p}<0.01$; ${ }^{*} * *_{p}<0.001$.

Abbreviations: LN, lymph nodes; LNE, lymph nodes enlargement. 
of patients with LN enlargement preferred the lung (10 patients, 35\%) and brain (6 patients, 21\%). A nomogram, including the variables independently related to LN enlargement, is shown in Figure 1C. The nomogram had a c-index of 0.747 (Supplementary Figure 2A), which indicated a relatively good ability to discriminate $(77.3 \%$ specificity and $62.7 \%$ sensitivity). The calibration plots of the nomogram prediction accuracy are shown in Figure 1D, and the results showed good agreement of the actual and predicted $\mathrm{LN}$ enlargement risks (mean absolute error $=0.015$ ).

\section{The Group with a Larger Mediastinum LN Size Had a Worse Survival of NSCLC Patients}

The 5-year cancer-specific survivals of the enlarged and non-enlarged groups were $75.3 \%$ and $92.8 \%(\mathrm{p}<0.0001)$, respectively, in NSCLC patients, compared by the Kaplan-Meier method with the Log rank test, and the KMcurve of the CSS is shown in Figure 2A. We divided all patients into three groups by $\mathrm{X}$-tile based on every parameter of LN size, including long diameter $(<10 \mathrm{~mm}$, $10 \sim 18 \mathrm{~mm},>18 \mathrm{~mm})$, short diameter $(<6 \mathrm{~mm}$, $6 \sim 10 \mathrm{~mm},>10 \mathrm{~mm})$, and volume $\left(<200 \mathrm{~mm}^{3}\right.$, 200 600 $\mathrm{mm}^{3},>600 \mathrm{~mm}^{3}$ ), with the survival curves shown in Figure 2B-D. We observed that every group with a larger LN size had a worse 5-year cancer-specific survivals by long diameter $(93.0 \%$ vs $79.6 \%$ vs $75.5 \%$; $<<$ $0.0001)$, short diameter $(93.0 \%$ vs $89.5 \%$ vs $71.5 \%$; $\mathrm{p}<0.0001)$, and volume $(93.0 \%$ vs $85.7 \%$ vs $73.5 \%$; $<<$ 0.0001 ), based on Kaplan-Meier method. The results of the competitive risk model (Figure 3A) showed the patients with LN enlargement still had a worse tumorassociated 5-year survival after excluding the interference of other no-tumor deaths. We also found there was a significant difference in tumor-associated 5-year survival between different sizes, including long diameters $(\mathrm{p}<$ $0.001)$, short diameter $(\mathrm{p}<0.001)$, and volume $(\mathrm{p}<$ 0.001 ) in subgroup analysis (Figure 3B-D). The nomogram of the competing risk model after the multivariate logistic analysis is shown in Supplementary Figure 2B. T stage $(p<0.001)$ and LN enlargement $(p=0.010)$ were good prognosis predictors for tumor-associated death. In addition, Figure 4 and Supplementary Figure 3 shows that the cumulative survival of NSCLC patients with other risk factors showed significant survival differences by KaplanMeier method according to sex $(\mathrm{p}<0.001)$, smoking $(\mathrm{p}<$ $0.001)$, pathology $(\mathrm{p}=0.021)$, T stage $(\mathrm{p}<0.001)$, adjuvant therapy $(p<0.001)$ and recurrence $(p<0.001)$. We
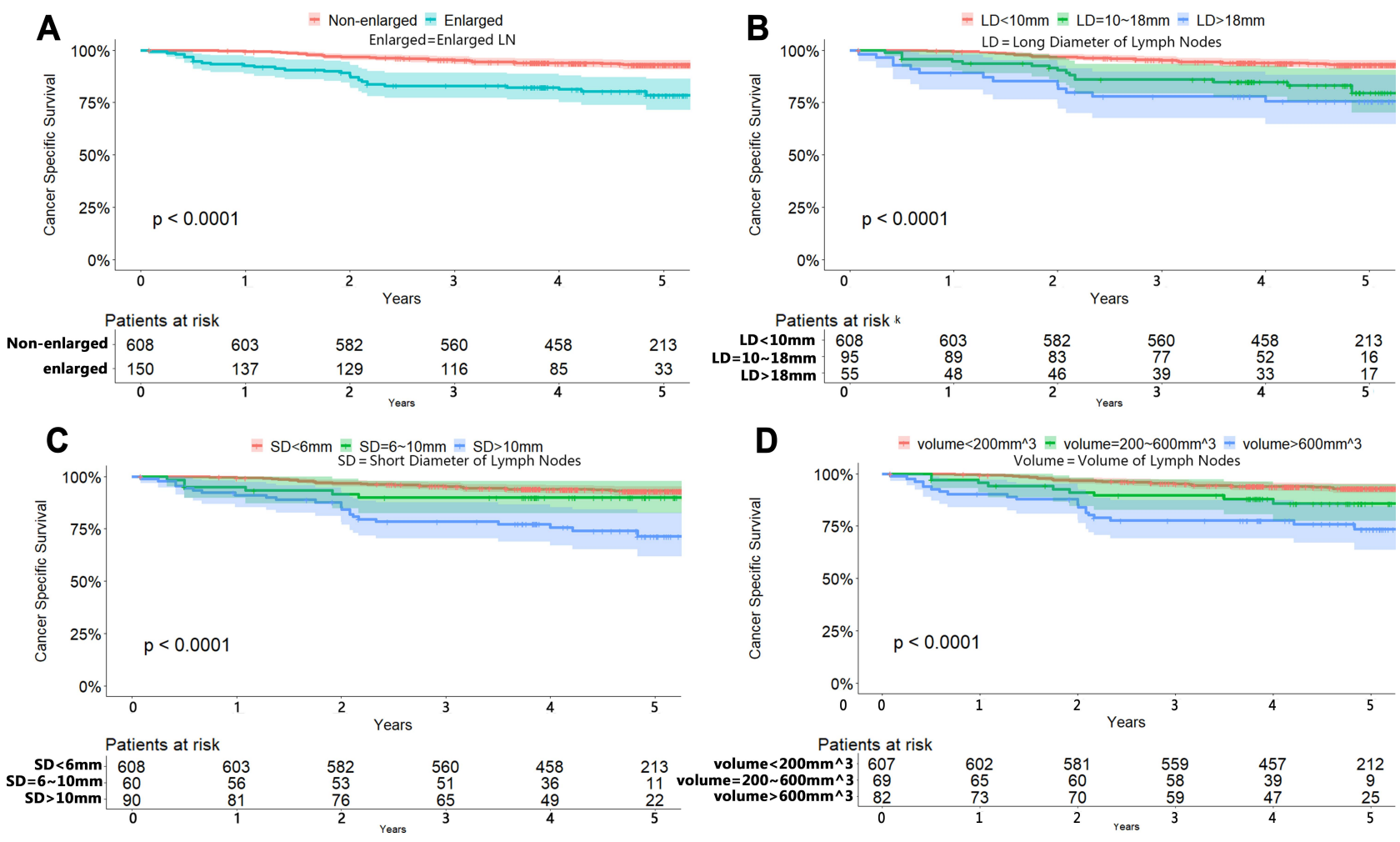

Figure 2 Kaplan-Meier estimate of cancer-specific survival of patients by LN enlargement (A), long diameter (B), short diameter (C) and volume (D). 

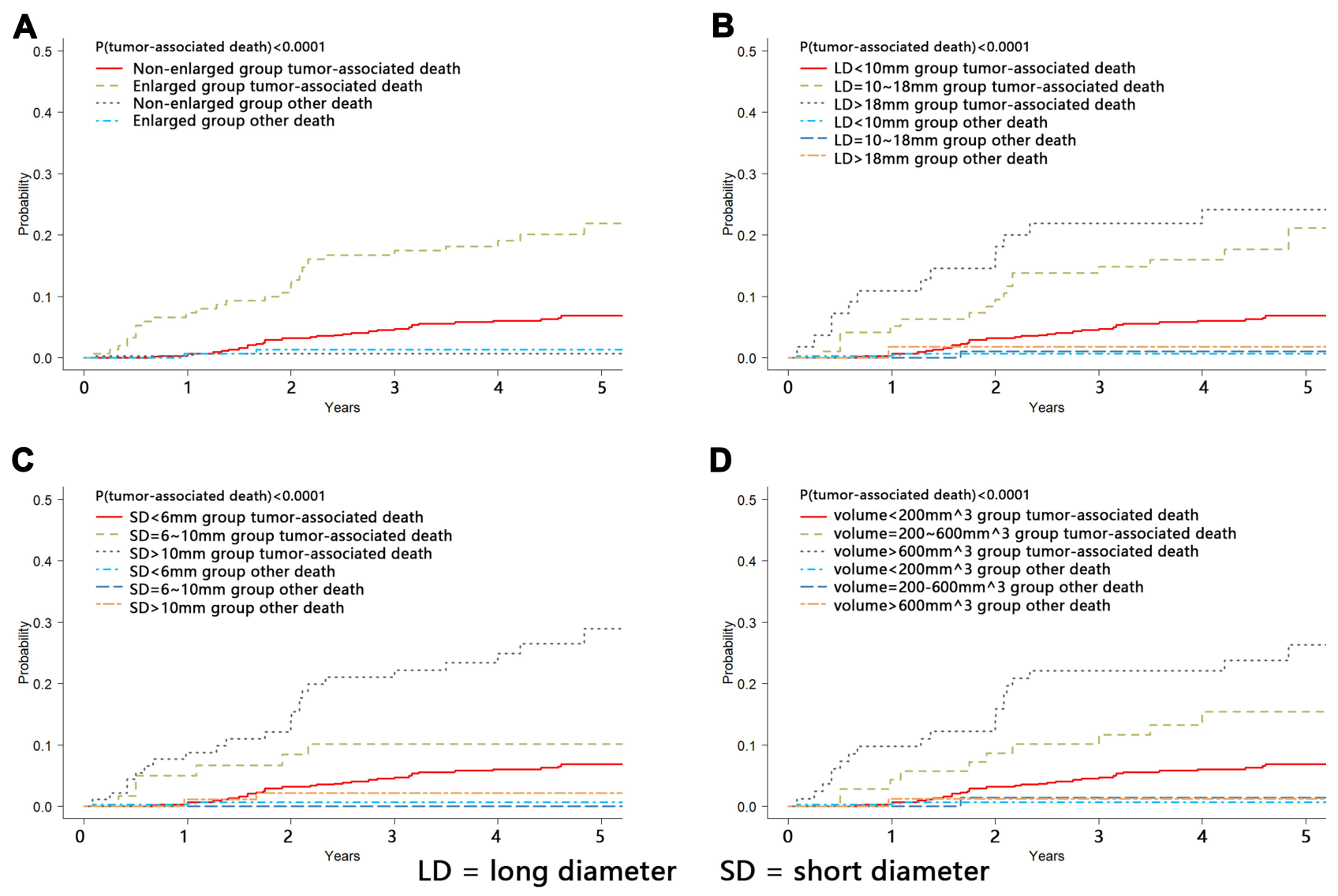

Figure 3 The cumulative incidence of LN enlargement $(\mathbf{A})$ and different $L N$ size including long diameter (B), short diameter (C) and volume (D) in competitive risk model.

also found the LN enlargement patients had a worse OS in the non-adjuvant therapy subgroup $(\mathrm{p}<0.001)$ and the adjuvant therapy subgroup $(\mathrm{p}=0.077)$ after Kaplan-Meier analyses (Supplementary Figure 2C and D).

\section{Volume Was a Valuable Predictive Factor After the MVA Cox Analysis}

Results of the univariate (UVA) and multivariate (MVA) Cox proportional hazards regressions are shown in Table 2. We found that sex $(\mathrm{p}<0.001)$, smoking $(\mathrm{p}<0.001)$, pathology $(\mathrm{p}=0.002)$, T stage $(\mathrm{p}<0.001)$, adjuvant therapy $(\mathrm{p}=0.029)$, recurrence $(\mathrm{p}<0.001)$ and volume of LN $(\mathrm{p}<0.001)$ were independently able to predict survival in UVA. MVA included all covariates with a value of $\mathrm{p}<0.1$ in UVA, and only $\mathrm{T}$ stage $(\mathrm{p}<0.001)$, adjuvant therapy $(\mathrm{p}=0.037)$, recurrence $(\mathrm{p}<0.001)$, and volume ( $\mathrm{p}$ $<0.001)$ were able to predict survival in MVA. The nomogram of the prognostic predictors in MVA is shown in Figure 5A. The 3- or 5-year CSSs were estimated by adding the points corresponding to the patient's characteristics. The Cox model had a c-index of 0.787 (95\% CI
0.738-0.836), which suggested relatively good discriminative ability. Calibration plots of the nomogram prediction accuracy are shown in Figure 5B-C, which indicated a good agreement of actual and predicted 3- and 5-year CSS.

\section{Discussion}

Our study investigated the predictive value of mediastinum LN size measured by CT in NSCLC patients with LN negative (shown in graphical abstract). We found that nearly $20 \%$ of NSCLC patients had enlarged negative mediastinum LN, and those patients with $\mathrm{LN}$ enlargement were still associated with a worse prognosis. The risk factors of LN enlargement included aging and squamous cell cancer. The patients with enlarged negative LN also had a higher risk of cancer relapse, and the first recurrence site was lung in patients with LN enlargement. Besides, the $\mathrm{LN}$ volume could be a very valuable prognostic, predictive factor in NSCLC patients. To our knowledge, this study is the largest study of the relationship between the LN size and the prognosis of NSCLC patients in N0 staging. 

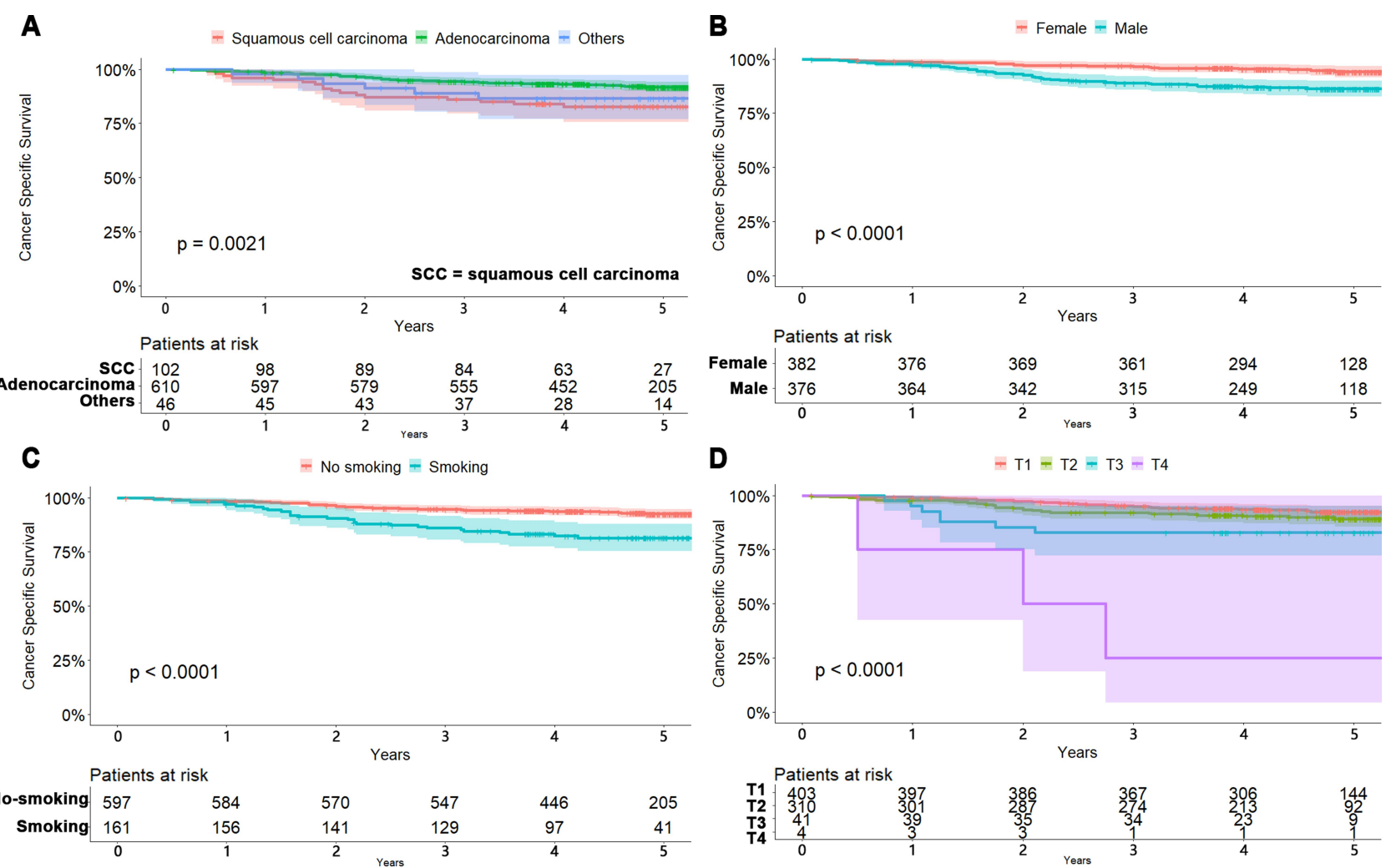

Figure 4 Kaplan-Meier estimate of cancer-specific survival of patients by pathology (A), sex (B), smoking (C) and T staging (D).

LN enlargement, a common phenomenon in NSCLC patients, has been reported to be a good indicator of $\mathrm{LN}$ metastasis. Verschakelen et al found that absolute LN size was significantly and positively correlated with metastasis. ${ }^{6,16}$ A meta-analysis of the prevalence of $\mathrm{LN}$ involvement for different sizes of enlarged LN in patients with NSCLC has been conducted. ${ }^{17}$ Nomori et al reported that the CT value and the MLE size predicted the LN metastasis with a precision of approximately $75 \% .{ }^{17}$ Ballegeer et al also described the CT characteristic of lymph nodes metastasis. ${ }^{18}$ VanMeerbeeck et al suggested the larger positive mediastinum LN could cause worse prognosis in $\mathrm{N} 2$ patients, but few studies focused on the N0 patients. ${ }^{7-9}$ In the present study, the risk factor of LN enlargement requires further characterization. Because of the limitation of CT, we suggested NSCLC patients with $\mathrm{LN}$ enlargement receive positron emission tomography/CT or endobronchial ultrasound from identifying the nature of the enlarged LN.

A higher possibility of LN enlargement was only associated with aging and squamous cell cancer using multivariate analysis. Some studies have focused on the clinical characteristic related to the $\mathrm{LN}$ enlargement, but the correlation between pathology and LN enlargement has been controversial. ${ }^{19-21}$ Tsutani et al suggested that the size of the solid tumor was an independent predictor of nodal enlargement. ${ }^{19-22}$ Still, the T staging did not correlate with $\mathrm{LN}$ enlargement in our data. We inferred the discrepancy was due to those patients in our study who had no LN involvement. It has been reported by a few studies that smoking was a risk factor of LN enlargement, but this conclusion is still controversial. Wainer Z's studies suggested that males with NSCLC had a higher possibility of metastasis than females with NSCLC. ${ }^{23}$ Heterogeneous tumor features between males and females with lung cancer also have been reported, which was opposite to our study. ${ }^{24}$ Some articles have reported the standard uptake value of primary tumors was associated with prognosis. ${ }^{25,26}$ Yusuke Takahashi' research demonstrated that maximum standardized uptake value is a predictive factor for occult nodal metastasis with an accuracy of $55-77 \% .{ }^{27}$ Masarykova et al found a correlation between the maximum standardized uptake value and the patient prognosis and lung cancer aggressiveness. ${ }^{28}$ Our previous study found the standard uptake value of primary tumor was associated with LN size, which may explain why the 
Table 2 The Result of UVA and MVA Cox Proportional Hazards Regression

\begin{tabular}{|c|c|c|c|c|}
\hline \multirow[t]{2}{*}{ Variables } & \multicolumn{2}{|l|}{ Univariable } & \multicolumn{2}{|l|}{ Multivariable } \\
\hline & HR (95\% Cl) & $\mathbf{P}$ & HR (95\% Cl) & $\mathbf{P}$ \\
\hline Age & $1.02(0.99 \sim 1.05)$ & 0.109 & $1.02(0.99 \sim 1.04)$ & 0.055 \\
\hline $\begin{array}{l}\text { Sex } \\
\qquad \begin{array}{l}\text { Female } \\
\text { Male }\end{array}\end{array}$ & $\begin{array}{l}\text { Reference } \\
2.7 \mid(I .62 \sim 4.56)\end{array}$ & $<0.001$ & $\begin{array}{l}\text { Reference } \\
\text { I.7I (0.92 3.19) }\end{array}$ & 0.092 \\
\hline $\begin{array}{c}\text { Smoking } \\
\text { Yes } \\
\text { No }\end{array}$ & $\begin{array}{l}2.73(1.70 \sim 4.38) \\
\text { Reference }\end{array}$ & $<0.001$ & $\begin{array}{l}\text { I.55 (0.86 2.78) } \\
\text { Reference }\end{array}$ & 0.147 \\
\hline $\begin{array}{l}\text { Family history } \\
\text { Yes } \\
\text { No }\end{array}$ & $\begin{array}{l}\text { I. } 45 \text { (0.53 3.98) } \\
\text { Reference }\end{array}$ & $0.47 I$ & & \\
\hline $\begin{array}{l}\text { Pathology } \\
\text { Squamous cell carcinoma } \\
\text { Adenocarcinoma } \\
\text { Others }\end{array}$ & $\begin{array}{l}\text { Reference } \\
2.50 \text { (I.46 4.32) } \\
1.82(0.78 \sim 4.27)\end{array}$ & 0.002 & $\begin{array}{l}\text { Reference } \\
\text { I.04 (0.49 1.80) } \\
\mathrm{I} .69(0.44 \sim 3.21)\end{array}$ & 0.728 \\
\hline $\begin{array}{l}\text { T stage } \\
\text { TI } \\
\text { T2 } \\
\text { T3 } \\
\text { T4 }\end{array}$ & $\begin{array}{l}\text { Reference } \\
1.43(0.86 \sim 2.38) \\
2.64(1.16 \sim 6.04) \\
16.8(5.11 \sim 55.48)\end{array}$ & $<0.001$ & $\begin{array}{l}\text { Reference } \\
1.07(0.64 \sim 1.8) \\
1.08(0.54 \sim 3.06) \\
10.11(2.93 \sim 34.89)\end{array}$ & $<0.001$ \\
\hline $\begin{array}{l}\text { Adjuvant therapy } \\
\text { Yes } \\
\text { No }\end{array}$ & $\begin{array}{l}2.14 \text { (I.34 3.44) } \\
\text { Reference }\end{array}$ & 0.002 & $\begin{array}{l}1.69(1.03 \sim 2.76) \\
\text { Reference }\end{array}$ & 0.038 \\
\hline $\begin{array}{l}\text { Volume } \\
\qquad 200 \mathrm{~mm}^{\wedge} 3 \\
200 \sim 600 \mathrm{~mm}^{\wedge} 3 \\
>600 \mathrm{~mm}^{\wedge} 3\end{array}$ & $\begin{array}{l}\text { Reference } \\
2.44(1.22 \sim 4.89) \\
4.32(2.52 \sim 7.38)\end{array}$ & $<0.001$ & $\begin{array}{l}\text { Reference } \\
1.98(1.06 \sim 3.99) \\
3.13(1.75 \sim 5.62)\end{array}$ & $<0.001$ \\
\hline
\end{tabular}

patients with LN enlargement in N0 staging had a worse CSS. We speculated the SUVmax value and LN size could synergistically predict the prognosis of NSCLC patients with negative LN, which need more PET/CT information to analyze.

Our results showed that patients with a larger LN size, including long diameter, short diameter, and volume, had a worse OS, which has also been reported in a few studies. Veronesi et al suggested that LN measuring $\geq 1 \mathrm{~cm}$ based on $\mathrm{CT}$ have an abnormal size, and thus, possibly indicates a poor prognosis. ${ }^{20}$ Some studies tried to use the size of LN measured in positron emission tomography/CT to predict the staging and prognoses of NSCLC patients. ${ }^{29-31}$ Still, the relationship of LN size measured by CT and the resulting prognosis have focused on the $\mathrm{LN}$ positive patients. Our study has explored the relationship between
LN size and prognosis in N0 staging patients, which was little mentioned. We also compared the predictive validity of long diameter, short diameter, and volume to obtain the most valuable prognoses. Still, we found that the predictive validity of these parameters was undifferentiated in integral survival analyses. In MVA Cox analysis, the larger volume and short diameter had a worse 5-year CSS and HR, while the different long diameters had no significant difference. Some studies have suggested that short diameter performed better in specificity than long diameter, ${ }^{32}$ and the volume had higher sensitivity and specificity due to combining the short diameter and long diameter. ${ }^{33}$ We also found that the volume of LN had a higher predictive value than a long diameter and short diameter.

Although the patients with LN enlargement in N0 staging had no LN metastasis, there was a significant cancer- 
A

Nomogram to predict CSS in NSCLC patients

$\beta(X-m)$ terms

$\begin{array}{cc}-0.5 \quad 0 \\ & \text { No }\end{array}$

$0 . \dot{5}$

1

1.5

2

Adjuvant therapy*

Volume***

T stage $\mathrm{e}^{\star \star *}$

Pathology

Volume $<200 \mathrm{~mm}^{\wedge} 3$
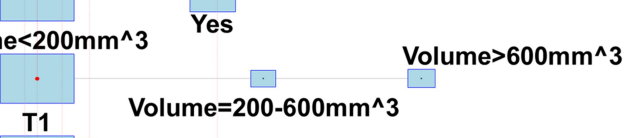

T2

Smoking

Gender

Age

${ }^{\mathrm{T} 2}$ cell carcinoma

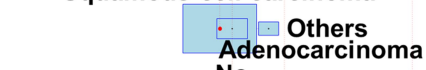

Ade
No

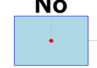

Female

Yes

Age

Total score

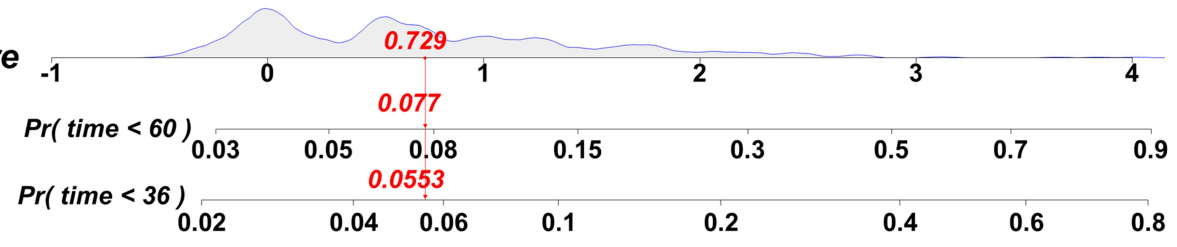

B

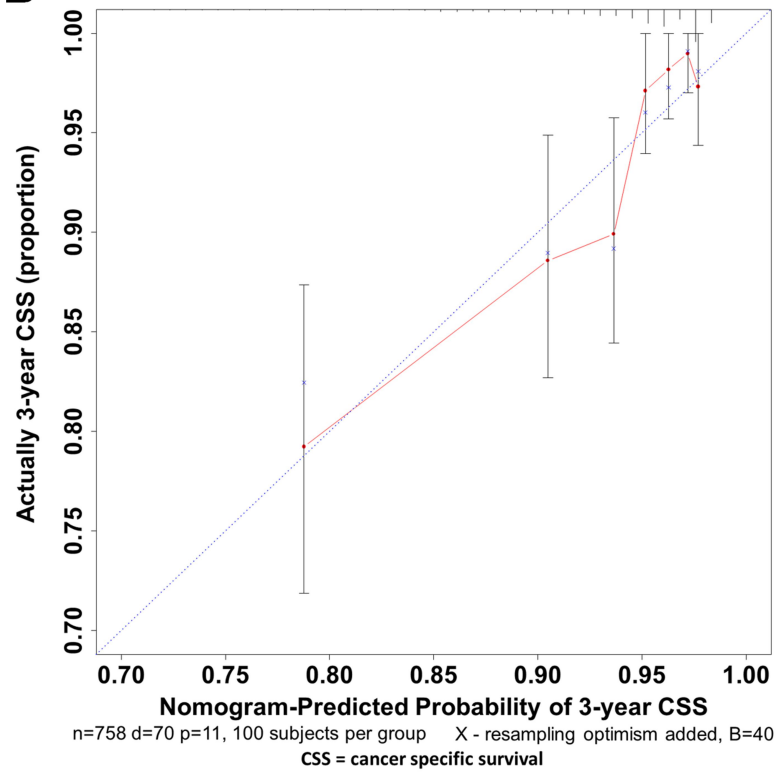

C

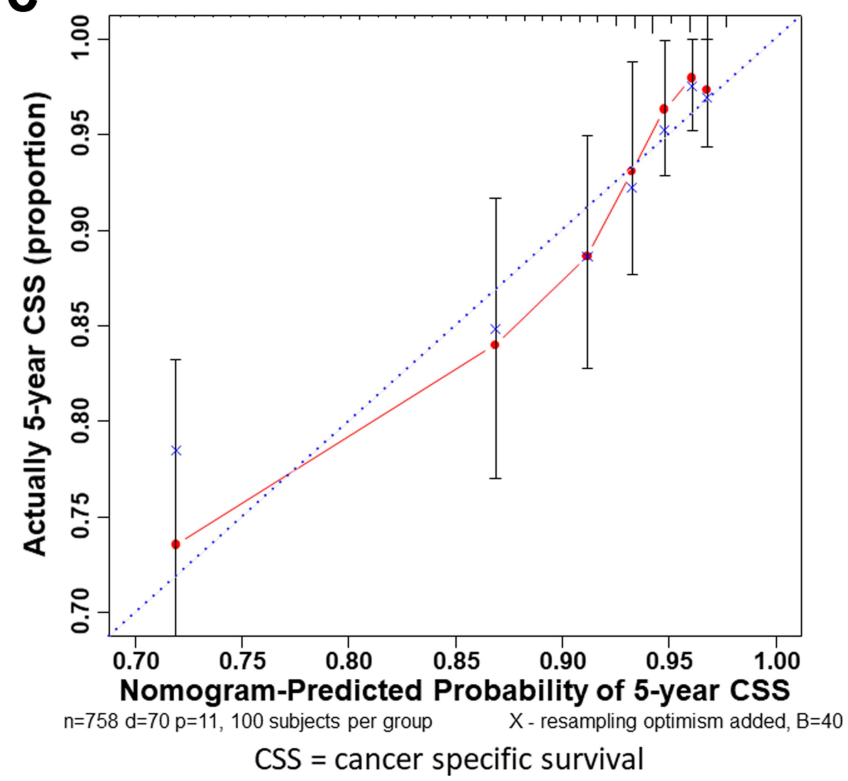

Figure 5 Nomogram to predict 3- and 5-year overall survival of patients with NSCLC $(\mathbf{A})$ and calibration plots $(\mathbf{B}, \mathbf{C}) * \mathrm{p}<0.05 ; * * * p<0.001$.

specific survival difference, as well as overall survival. Analysis in the competing risk model suggested that tumor-associated death was associated with LN size. In previous studies, smoking, inflammation, and involvement were common risk factors of $\mathrm{LN}$ enlargement. We have analyzed the relation to smoking and LN enlargement and found no correlation. Besides, we could not totally define the infection or inflammation status of the patients during surgery, and we could not entirely exclude the relationship of inflammation status and LN enlargement. LN enlargement Patients with COPD or other inflammation diseases were account for a small proportion in our department. 
Koike et al suggested that the tumor size could be a valuable predictive factor for mediastinum LN metastasis in stage IA NSCLC patients. ${ }^{34}$ However, there was no apparent relationship between the tumor size to $\mathrm{LN}$ enlargement in our data after logistic analyses. Correlation analysis suggested the LN enlargement was related to tumor relapse. We have excluded the possibility of $\mathrm{LN}$ involvement as far as possible. Our pathology assessment was completed by two experienced pathologists at least, and the gap of the LN slice was tiny. They usually cut the $\mathrm{LN}$ every $2 \sim 3 \mathrm{~mm}$ if the size of $\mathrm{LN}$ is more than $5 \mathrm{~mm}$. They just cut LN in half while the size of LN is less than $5 \mathrm{~mm}$. Our results suggested that we might need to detect more slices for the patients with LN enlargement to eliminate the possible micrometastasis.

Therefore, we propose that the worse CSS in NSCLC patients with enlarged negative LN could be partially explained by the phenomenon of LN micrometastasis or the potential basic disease. ${ }^{35,36} \mathrm{LN}$ micrometastasis or the immune microenvironment of basic diseases such as granulomatous may induce the tumor cell invasion and migration and cause the relapse of cancer. Even so, the LN enlargement may be related to the slight missing tumor cell, but it is worthy of discussing further whether tiny tumor cells could cause LN enlargement. Verma et al suggested that LN mildly increased in size was more likely to harbor disease, but they did not have an adequate concentration of neoplastic cells. ${ }^{37}$ Some studies reported that LN granulomatous inflammation was associated with metastasis of breast cancer, renal cell cancer, and lymphomas. ${ }^{38}$ Additionally, historical studies have shown an increased risk of cancer in patients previously diagnosed with sarcoidosis, especially lung cancer and lymphoma. ${ }^{39}$ Besides, LN false-negatives had been reported in some studies, and the micropapillary component was one of the significant predictors of unexpected node-positive diseases. ${ }^{22,39}$

The major limitation of this study was that the sizes of LN were artificially measured using thinner CT, which could cause some systematic errors. These errors could influence the grouping of LN in subgroup analysis. We hoped the LN size measured by artificial intelligence could be fulfilled in the future. Second, our study was retrospective, and as a single-center study, our study failed to validate the model using a larger cohort, limiting the representation and generality of our results. We have included as many patients as possible (768 patients) in our study and we expect other studies could verify our findings. Thirdly, we are not sure whether the LN size could change as time goes by because most patients only received the chest CT scan once before surgery. Besides, the volume of LN was estimated using an equation, which could cause some bias. Finally, only $34.9 \%$ of NSCLC patients in our study had a PET/CT scan, which limited further exploration.

\section{Conclusion}

Nearly $20 \%$ of N0 patients had mediastinum LN enlargement, and the patients with a larger mediastinum LN had a worse 5-year CSS and had a higher risk of tumor relapse. The risk factors of mediastinum LN enlargement involved aging and squamous cell carcinoma. The volume of the LN measured in CT was a more valuable prognostic factor of NSCLC patients than long diameters or short diameters.

\section{Abbreviations}

LN, lymph nodes; LNE, lymph nodes enlargement; NSCLC, non-small cell lung cancer; OS, overall survival; CSS, cancer-specific survival.

\section{Acknowledgments}

We thank you for the statistical review by Dr. Runmei Li, Department of Biostatistics, Public Health, Fudan University, Shanghai, P. R. China. This work was supported by the Research and Development Fund of Zhongshan Hospital, Fudan University (Grant number 2018ZSLC28 and 2016ZSFZ56). We thank the International Science Editing (http://www.internationals cienceediting.com) for editing this manuscript.

\section{Author Contributions}

All authors made a significant contribution to the work reported, whether that is in the conception, study design, execution, acquisition of data, analysis and interpretation, or in all these areas; took part in drafting, revising or critically reviewing the article; gave final approval of the version to be published; have agreed on the journal to which the article has been submitted; and agree to be accountable for all aspects of the work.

\section{Disclosure}

All authors have nothing to disclose with regard to commercial support. The authors report no conflicts of interest for this work.

\section{References}

1. Henley SJ, Ward EM, Scott S, et al. Annual report to the nation on the status of cancer, part I: national cancer statistics. Cancer Am Cancer Soc. 2020;126(10):2225-2249. 
2. Siegel RL, Miller KD, Jemal A. Cancer statistics, 2020. CA Cancer J Clin. 2020;70(1):7-30. doi:10.3322/caac.21590

3. Bade BC, Thomas DD, Scott JB, Silvestri GA. Increasing physical activity and exercise in lung cancer: reviewing safety, benefits, and application. $J$ Thorac Oncol. 2015;10(6):861-871. doi:10.1097/ JTO.0000000000000536

4. Fukui T, Kato K, Okasaka T, et al. Predictors for hilar/intrapulmonary lymph node metastasis in discrete type of clinical N1 non-small cell lung cancer. Gen Thorac Cardiovasc Surg. 2017;65(11):640-645. doi:10.1007/s11748-017-0827-4

5. Detterbeck FC, Stratton K, Giroux D, et al. The IASLC/ITMIG thymic epithelial tumors staging project: proposal for an evidence-based stage classification system for the forthcoming (8th) edition of the TNM classification of malignant tumors. $J$ Thorac Oncol. 2014;9(9 Suppl 2): S65-S72. doi:10.1097/JTO.0000000000000290

6. Verschakelen JA, Bogaert J, De Wever W. Computed tomography in staging for lung cancer. Eur Respir J Suppl. 2002;35:40s-48s. doi:10.1183/09031936.02.00270802

7. Albain KS, Swann RS, Rusch VW, et al. Radiotherapy plus chemotherapy with or without surgical resection for stage III non-smallcell lung cancer: a Phase III randomised controlled trial. Lancet. 2009;374(9687):379-386. doi:10.1016/S0140-6736(09)60737-6

8. van Meerbeeck JP, Kramer GW, Van Schil PE, et al. Randomized controlled trial of resection versus radiotherapy after induction chemotherapy in stage IIIA-N2 non-small-cell lung cancer. $J$ Natl Cancer Inst. 2007;99(6):442-450. doi:10.1093/jnci/djk093

9. Shafique MR, Robinson LA, Antonia S. Durvalumab: a potential maintenance therapy in surgery-ineligible non-small-cell lung cancer. Cancer Manag Res. 2018;10:931-940. doi:10.2147/CMAR. S148009

10. Pham TD, Watanabe Y, Higuchi M, Suzuki H. Texture analysis and synthesis of malignant and benign mediastinal lymph nodes in patients with lung cancer on computed tomography. Sci Rep. 2017;7:43209. doi:10.1038/srep43209

11. Furukawa MK, Furukawa M. Diagnosis of lymph node metastases of head and neck cancer and evaluation of effects of chemoradiotherapy using ultrasonography. Int $J$ Clin Oncol. 2010;15(1):23-32. doi:10.1007/s10147-009-0017-1

12. Ganeshalingam S, Koh DM. Nodal staging. Cancer Imaging. 2009;9:104-111. doi:10.1102/1470-7330.2009.0017

13. Genereux GP, Howie JL. Normal mediastinal lymph node size and number: CT and anatomic study. Am J Roentgenol. 1984;142 (6):1095-1100. doi:10.2214/ajr.142.6.1095

14. Ziyade S, Pinarbasili NB, Ziyade N, et al. Determination of standard number, size and weight of mediastinal lymph nodes in postmortem examinations: reflection on lung cancer surgery. J Cardiothorac Surg. 2013;8:94. doi:10.1186/1749-8090-8-94

15. Camp RL, Dolled-Filhart M, Rimm DL. X-tile: a new bio-informatics tool for biomarker assessment and outcome-based cut-point optimization. Clin Cancer Res. 2004;10(21):7252-7259. doi:10.1158/1078-0432.CCR-04-0713

16. Mattes MD, Weber WA, Foster A, et al. A predictive model for lymph node involvement with malignancy on PET/CT in non-smallcell lung cancer. $J$ Thorac Oncol. 2015;10(8):1207-1212.

17. Nomori H, Watanabe K, Ohtsuka T, Naruke T, Suemasu K, Uno K. The size of metastatic foci and lymph nodes yielding false-negative and false-positive lymph node staging with positron emission tomography in patients with lung cancer. $J$ Thorac Cardiovasc Surg. 2004;127(4):1087-1092. doi:10.1016/j.jtcvs.2003.08.010

18. Ballegeer EA, Adams WM, Dubielzig RR, Paoloni MC, Klauer JM, Keuler NS. Computed tomography characteristics of canine tracheobronchial lymph node metastasis. Vet Radiol Ultrasound. 2010;51 (4):397-403. doi:10.1111/j.1740-8261.2010.01675.x

19. Hanagiri T, Takenaka M, Oka S, et al. Prognostic significance of lymphovascular invasion for patients with stage I non-small cell lung cancer. Eur Surg Res. 2011;47(4):211-217. doi:10.1159/000333367
20. Veronesi G, Maisonneuve P, Pelosi G, et al. Screening-detected lung cancers: is systematic nodal dissection always essential? $J$ Thorac Oncol. 2011;6(3):525-530. doi:10.1097/JTO.0b013e318206dbcc

21. Osarogiagbon RU, Ramirez RA, Wang CG, et al. Size and histologic characteristics of lymph node material retrieved from tissue discarded after routine pathologic examination of lung cancer resection specimens. Ann Diagn Pathol. 2014;18(3):136-139. doi:10.1016/j. anndiagpath.2014.02.004

22. Tsutani Y, Miyata Y, Nakayama H, et al. Prediction of pathologic node-negative clinical stage IA lung adenocarcinoma for optimal candidates undergoing sublobar resection. J Thorac Cardiovasc Surg. 2012;144(6):1365-1371. doi:10.1016/j.jtcvs.2012.07.012

23. Wainer Z, Wright GM, Gough K, et al. Sex-dependent staging in non-small-cell lung cancer; analysis of the effect of sex differences in the eighth edition of the tumor, node, metastases staging system. Clin Lung Cancer. 2018;19(6):e933-e44. doi:10.1016/j.cllc.2018.08.004

24. Frega S, Dal Maso A, Ferro A, Bonanno L, Conte P, Pasello G. Heterogeneous tumor features and treatment outcome between males and females with lung cancer (LC): do gender and sex matter? Crit Rev Oncol Hematol. 2019;138:87-103.

25. Eze C, Taugner J, Roengvoraphoj O, et al. Initial report on feasibility of PET/CT-based image-guided moderate hypofractionated thoracic irradiation in node-positive non-small cell lung cancer patients with poor prognostic factors and strongly diminished lung function: a retrospective analysis. Radiat Oncol. 2019;14(1):163. doi:10.1186/ s13014-019-1304-2

26. Li R, Lin J, Wang L, Zheng X, Tang K. The association between $18 \mathrm{~F}$-fluorodeoxyglucose PET intratumoral metabolic heterogeneity and pathological parameters in non-small cell lung cancer. $\mathrm{Nucl}$ Med Commun. 2019;40(10):1022-1028. doi:10.1097/ MNM.0000000000001058

27. Takahashi Y, Suzuki S, Matsutani N, Kawamura M. 18Ffluorodeoxyglucose positron emission tomography/computed tomography in the evaluation of clinically node-negative non-small cell lung cancer. Thoracic Cancer. 2019;10(3):413-420. doi:10.1111/17597714.12978

28. Masarykova A, Scepanovic D, Povinec P, Bires P, Lederleitner D, Pobijakova M. Tumour metabolic activity measured by fluorodeoxyglucose positron emission tomography for radiotherapy planning as a prognostic factor for locally advanced non-small cell lung cancer. Bratisl Lek Listy. 2018;119(3):133-138.

29. Lv YL, Yuan DM, Wang K, et al. Diagnostic performance of integrated positron emission tomography/computed tomography for mediastinal lymph node staging in non-small cell lung cancer: a bivariate systematic review and meta-analysis. $J$ Thorac Oncol. 2011;6 (8):1350-1358. doi:10.1097/JTO.0b013e31821d4384

30. Truong MT, Viswanathan C, Erasmus JJ. Positron emission tomography/computed tomography in lung cancer staging, prognosis, and assessment of therapeutic response. $J$ Thorac Imaging. 2011;26 (2):132-146. doi:10.1097/RTI.0b013e3182128704

31. Toloza EM, Harpole L, Detterbeck F, McCrory DC. Invasive staging of non-small cell lung cancer: a review of the current evidence. Chest. 2003;123(1 Suppl):157S-166S. doi:10.1378/chest.123.1_suppl.157S

32. Liu J, Wang Z, Shao H, Qu D, Liu J, Yao L. Improving CT detection sensitivity for nodal metastases in oesophageal cancer with combination of smaller size and lymph node axial ratio. Eur Radiol. 2018;28 (1):188-195. doi:10.1007/s00330-017-4935-4

33. Suemitsu R, Takeo S, Matsuzawa H, Yamaguchi M, Momosaki S, Uesugi N. Can a thoracic surgeon identify lymph node metastases during surgery based on their size? Analysis of 844 metastatic and 10,462 nonmetastatic lymph nodes. $J$ Thorac Oncol. 2010;5 (3):349-353. doi:10.1097/JTO.0b013e3181c6b86b

34. Koike T, Koike T, Yamato Y, Yoshiya K, Toyabe S. Predictive risk factors for mediastinal lymph node metastasis in clinical stage IA non-small-cell lung cancer patients. $J$ Thorac Oncol. 2012;7 (8):1246-1251. doi:10.1097/JTO.0b013e31825871de 
35. Anami K, Yamashita S, Yamamoto S, et al. Contralateral mediastinal lymph node micrometastases assessed by video-assisted thoracoscopic surgery in stage I non-small cell left lung cancer. Eur $J$ Cardiothorac Surg. 2013;43(4):778-782.

36. Nentwich MF, Bohn BA, Uzunoglu FG, et al. Lymphatic invasion predicts survival in patients with early node-negative non-small cell lung cancer. J Thorac Cardiovasc Surg. 2013;146(4):781-787. doi:10.1016/j.jtcvs.2013.04.037

37. Verma V, Schonewolf CA, Cushman TR, et al. Impact of enlarged nonhypermetabolic lymph nodes on outcomes after stereotactic body radiotherapy for early-stage non-small-cell lung cancer. Clin Lung Cancer. 2018;19(6):502-510. doi:10.1016/j.cllc.2018.07.005
38. Krvavac A, Munzer K, Miller A, Poddar N, Jamkhana Z, Patolia S. The concurrence of granulomatous inflammation in intrathoracic lymph nodes with regional metastasis from primary lung cancer in surgically resected specimens. Adv Respir Med. 2018;86(5):215-219. doi:10.5603/ARM.2018.0034

39. Brincker H. Sarcoid reactions and sarcoidosis in hodgkin's disease and other malignant lymphomata. Br J Cancer. 1972;26(2):120-123. doi:10.1038/bjc. 1972.18

\section{Publish your work in this journal}

Cancer Management and Research is an international, peer-reviewed open access journal focusing on cancer research and the optimal use of preventative and integrated treatment interventions to achieve improved outcomes, enhanced survival and quality of life for the cancer patient.
The manuscript management system is completely online and includes a very quick and fair peer-review system, which is all easy to use. Visit http://www.dovepress.com/testimonials.php to read real quotes from published authors. 